\title{
Left Ventricular Hypertrophy in Chronic Kidney Disease Patients: From Pathophysiology to Treatment
}

\author{
Luca Di Lullo $^{a}$ Antonio Gorini ${ }^{a}$ Domenico Russo ${ }^{b}$ Alberto Santoboni ${ }^{a}$ \\ Claudio Ronco ${ }^{c}$ \\ ${ }^{a}$ Department of Nephrology and Dialysis, L. Parodi Delfino Hospital, Colleferro, b Division \\ of Nephrology, University of Naples Federico II, Naples, and ' ${ }^{\mathrm{C}}$ International Renal Research \\ Institute, S. Bortolo Hospital, Vicenza, Italy
}

\section{Key Words}

Left ventricular hypertrophy · Chronic kidney disease · Type 4 cardiorenal syndrome .

Echocardiography

\begin{abstract}
Cardiovascular diseases represent the main causes of morbidity and mortality in patients with chronic kidney disease (CKD). According to a well-established classification, cardiovascular involvement in CKD can be set in the context of cardiorenal syndrome type 4. Left ventricular hypertrophy (LVH) represents a key feature to provide an accurate picture of systolic-diastolic left heart involvement in CKD patients. Cardiovascular involvement is present in about 80\% of prevalent hemodialysis patients, and it is evident in CKD patients since stage IIIb-IV renal disease (according to the K/DOQI CKD classification). According to the definition of cardiorenal syndrome type 4, kidney disease is detected before the development of heart failure, although timing of the diagnosis is not always possible. The evaluation of LVH is a bit heterogeneous, and few standard imaging methods can provide the accuracy of either CT- or MRI-derived left ventricular mass. Key principles in the treatment of LVH in CKD patients are mainly based on anemia and blood pressure control, together with the management of secondary hyperparathyroidism and sudden cardiac death prevention. This review is mainly focused on the clinical aspects of CKD-related LVH to provide practical guidelines both for cardiologists and nephrologists in the daily clinical approach to CKD patients.
\end{abstract}




\section{CardioRenal Medicine}

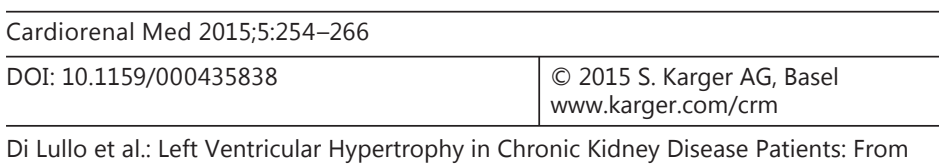

Di Lullo et al.: Left Ventricular Hyp
Pathophysiology to Treatment

\section{Introduction}

Cardiovascular diseases such as coronary artery disease, congestive heart failure, arrhythmias and sudden cardiac death represent the main causes of morbidity and mortality in patients with chronic kidney disease (CKD). According to a well-established classification of cardiorenal syndrome, cardiovascular involvement in CKD is also defined as cardiorenal syndrome type 4 (chronic renocardiac).

The term known as 'cardiorenal syndrome' (CRS) includes a broad spectrum of diseases in which heart and kidney are both involved. A consensus conference of the Acute Dialysis Quality Initiative Group [1] has recently proposed the term 'cardiorenal syndrome' to define a clinical overlap between kidney and heart dysfunction. A clear classification of CRS is crucial and its wide correct application is required to allow correct interactions between cardiologists and nephrologists. The CRS classification (table 1) essentially describes two main groups, cardiorenal and renocardiac CRS, on the basis of the primum movens of the disease (cardiac or renal); then it is divided into acute and chronic according to the disease onset. Left ventricular hypertrophy $(\mathrm{LVH})$ represents the key feature in uremic cardiopathy and it is related to CRS type 4 (chronic renocardiac/cardiorenal syndrome).

Cardiovascular complications can occur at any stage of CKD irrespective of glomerular filtration rate (GFR) levels.

According to the definition of CRS type 4, kidney disease is detected before the development of heart failure. However, timing of the diagnosis is not always possible.

\section{Epidemiology}

It should be clear by now that there is a close relationship between CKD and increased risk for cardiovascular disease: major cardiac events actually represent almost $50 \%$ of the causes of death in CKD patients [2].

From the early stages of CKD to end-stage renal disease (ESRD), cardiovascular involvement is present, in part due to the aging population and in part due to higher rates of diabetic, dyslipidemic and hypertensive patients among the CKD population [3].

The HEMO study clearly demonstrated a high prevalence (about $80 \%$ ) of cardiovascular disease in hemodialysis patients related to age, prevalence of diabetes and dialytic age [4]. Stage I-IV CKD patients show lower degrees of cardiovascular involvement compared to dialysis patients (both hemodialysis and peritoneal dialysis), which becomes more evident as the GFR falls below $60 \mathrm{ml} / \mathrm{min} / 1.73 \mathrm{~m}^{2}[5,6]$.

A meta-analysis by Tonelli et al. [7] conducted on 1.4 million patients found higher mortality rates for all causes, which is correlated with decreasing eGFR levels and with a relative death odds ratio of $1.9,2.6$ and 4.4 for GFR levels of 80,60 and $40 \mathrm{ml} / \mathrm{min}$, respectively.

Cardiovascular risk is particularly evident in patients with stage IIIb-IV renal disease (according to the K/DOQI CKD classification) and in those who underwent renal replacement therapy (hemodialysis, peritoneal dialysis and transplant) [8].

In the study by Go et al. [9], the risk of adverse cardiovascular events was $43 \%$ higher in patients with a GFR between 45 and $59 \mathrm{ml} / \mathrm{min} / 1.73 \mathrm{~m}^{2}$ and $343 \%$ higher in those with a GFR $<15 \mathrm{ml} / \mathrm{min} / 1.73 \mathrm{~m}^{2}$ compared to the control group with a normal GFR. Stage V CKD patients, not on renal replacement therapy, showed mortality rates similar to those on dialysis therapy. Cardiovascular diseases may account for $50 \%$ of deaths in CKD patients regardless of biological age [10].

The Kidney Early Evaluation Program (KEEP) enrolled and screened about 100,000 people for kidney disease reporting various comorbid diseases including congestive heart 
Table 1. CRS classification

CRS general definition

A pathophysiologic disorder of the heart and kidneys whereby acute or chronic dysfunction in one organ may induce acute or chronic dysfunction in the other organ

CRS type I (acute CRS)

Abrupt worsening of cardiac function (e.g. acute cardiogenic shock or acutely decompensated congestive heart failure) leading to acute kidney injury

CRS type II (chronic CRS)

Chronic abnormalities in cardiac function (e.g. chronic congestive heart failure) causing progressive and potentially permanent CKD

CRS type III (acute renocardiac syndrome)

Abrupt worsening of renal function (e.g. acute kidney ischemia or glomerulonephritis) causing acute cardiac disorder (e.g. heart failure, arrhythmia, ischemia)

CRS type IV (chronic renocardiac syndrome)

CKD (e.g. chronic glomerular or interstitial disease) contributing to decreased cardiac function, cardiac hypertrophy and/or increased risk of adverse cardiovascular events

CRS type V (secondary CRS)

Systemic condition (e.g. diabetes mellitus, sepsis) causing both cardiac and renal dysfunction

failure; the data analysis showed a cardiovascular disease risk rising by $15 \%$ for every increasing stage of CKD [11].

The Chronic Renal Insufficiency Cohort (CRIC) study investigators focused their attention on 190 patients presenting with stage III to ESRD and performed serial echocardiographic evaluations; in the 2 years' observation period during which the patients shifted from stage $\mathrm{V}$ to ESRD, the ejection fraction (EF) dropped from 53 to $50 \%$ [12].

Cardiovascular events are not only restricted to ESRD; early CKD stages are also associated with variable degrees of heart failure as underlined in the Atherosclerosis Risk in Communities (ARIC) population study [13] that focused on incident cardiovascular events in about 15,000 subjects (subjects with preexisting heart failure were dropped out). Statistical analysis found an increase in heart failure in subjects with an eGFR $<60 \mathrm{ml} / \mathrm{min} / 1.73 \mathrm{~m}^{2}$.

Cox regression analysis demonstrated a relative hazard of incident heart failure of 1.10 in subjects with a GFR range of $60-89 \mathrm{ml} / \mathrm{min} / 1.73 \mathrm{~m}^{2}$ and of 1.94 in those with a GFR $<60$ $\mathrm{ml} / \mathrm{min} / 1.73 \mathrm{~m}^{2}$.

The prevalence of LVH is estimated to be between 16 and 31\% in individuals with a GFR $>30 \mathrm{ml} / \mathrm{min}$; it increases to $60-75 \%$ prior to starting renal replacement therapy, and rises to $90 \%$ after the initiation of dialysis [14]. Foley et al. [15] followed 596 incident hemodialysis patients with no prior history of cardiac disease to investigate whether the incidence of LVH correlates with the duration of dialysis. After 18 months of dialysis, the author reported that $62 \%$ of the patients had an increased LV mass volume index and that $49 \%$ of them developed overt LV failure. These observations raise the question of whether dialysis therapy develops into LVH in ESRD patients [16].

\section{Pathophysiology of LVH in CKD Patients}

Echocardiographic abnormalities (impairment of EF and increased end-systolic and enddiastolic LV volumes) are frequently reported from the early stages of CKD to ESRD. 

Di Lullo et al.: Left Ventricular Hypertrophy in Chronic Kidney Disease Patients: From
Pathophysiology to Treatment

Pathophysiologic factors involved in LVH of CKD and ESRD patients have generally been divided into 3 categories [17-19]: (1) related to afterload, (2) related to preload, and (3) not related to afterload or preload. The ones in the first category are represented by an increase in systemic arterial resistance, elevated arterial blood pressure, and reduced large-vessel compliance [17-20] related in part to aortic 'calcification', which is typical in CKD patients; all these factors result in myocardial cell thickening and concentric LV remodeling often together with activation of the intracardiac renin-angiotensin system $[19,21]$.

Oxidative stress and xanthine oxidase activation as well as the phosphodiesterase- 5 pathway may also be involved in the development of LVH [22] as demonstrated by pharmacological effects of sildenafil therapy that attenuates LVH [23]. Among the preload-related factors, the role of intravascular volume expansion (salt and fluid loading) has to be underlined, as well as secondary anemia and the presence of arterovenous fistulas [14, 24, 25], resulting in myocardial cell lengthening and eccentric or asymmetric LV remodeling. Both afterload- and preload-related factors operate with additive and synergistic effects.

As a result, myocardial hypertrophy induces the activation of cellular apoptotic signals and activates metabolic pathways able to increase extracellular matrix production up to fibrosis [26, 27]. Fibrosis leads to progressive impairment in contractility with stiffening of the myocardial wall, systolic and diastolic dysfunction, dilated cardiomyopathy and congestive heart failure [28]. It also leads to disturbances of cardiac electrophysiology because of ventricular electrical conduction impairment and to the development of re-entry pathway arrhythmias [17].

Renin-angiotensin-aldosterone system activation induces hyperaldosteronemia promoting cardiac fibrosis through the generation of signals leading to profibrotic transforming growth factor production [21]. The LVH can also be promoted by iron and/or erythropoietin [29] or vitamin D deficiency [30]. Calcimimetics therapy can induce cardiac fibrosis regression without affecting the left ventricular mass [31]. The presence of arterovenous fistulas can contribute to the development of LVH because of excess blood flow that increases the myocardial workload [14].

Arterial stiffness is mainly caused by increased collagen production and deposition with a consequent raise in peripheral resistance due to vasoconstriction. Stiffness can also be caused by elevations in plasma sodium concentration (>135 mmol/l) directly affecting the vascular endothelium and nitric oxide release [32]. The modulation of plasma sodium concentrations during dialysis sessions can produce positive effects on blood pressure levels and left ventricular compliance [33].

Recent studies have pointed up novel biomarkers involved in the pathogenesis of LVH. One of these is represented by FGF23, a member of the fibroblast growth factor family primarily involved in CKD-mineral and bone disorder (MBD) and secondary hyperparathyroidism. The pathogenesis of CKD-MBD has always been ascribed to a decline in 1,25-dihydroxyvitamin D [1,25(OH)2 D3] levels leading to increases in serum parathyroid hormone (PTH) and subsequent alterations in calcium and phosphorus metabolism [34, 35]. Vitamin D deficiency, together with secondary hyperparathyroidism and hyperphosphatemia, was reported as a main factor contributing to high cardiovascular risks in CKD patients [36]. The discovery of FGF23 changed what has been described above because of its role in secondary hyperparathyroidism pathophysiology. At the present time, FGF23 represents the earliest detected serum abnormality in patients with CKD-MBD [37] and FGF23 levels rise before any changes in PTH, 1,25(OH)2 D3, or serum phosphate levels are detected [38]. FGF23 is implicated in the regulation, growth, and differentiation of cardiac myocytes holding paracrine functions in the kidneys because of its phosphaturic properties; it blocks vitamin $\mathrm{D}_{3}$ synthesis and inhibits proximal nephron reabsorption [39]. 

Di Lullo et al.: Left Ventricular Hypertrophy in Chronic Kidney Disease Patients: From
Pathophysiology to Treatment

Serum levels of FGF23 increase gradually as kidney function decreases. FGF23 levels are often 2-5 times the normal level during early and intermediate stages of CKD easily reaching more than 200 times the normal levels in cases of advanced renal failure [40]. First data about correlations between FGF23 levels and mortality were reported in 2008 when Gutierrez et al. [40] evaluated FGF23 levels in over 400 incident hemodialysis patients. The increased FGF23 levels at the beginning of dialysis were independently associated with a significantly increased risk of mortality during the first year on dialysis.

Results of these observations were confirmed in two large longitudinal cohort studies in predialysis CKD patients. The CRIC study enrolled 3,879 patients with CKD stages 2-4 with a median follow-up of 3.5 years [41]; higher levels of FGF23 were associated independently with a greater risk of death. In a post-hoc analysis of the HOST study [42], a strong relation between higher FGF23 levels and higher risks of cardiovascular events was found. Elevated C-terminal FGF23 levels were also strongly associated with an increased risk of acute myocardial infarction and lower-extremity amputation.

The results of several clinical trials suggest a close relationship between FGF23 and LVH. One of the above-cited trials included 124 hemodialysis patients in whom the FGF23 levels were independently associated with the degree of LVH [43]. Another study of 162 predialysis CKD patients showed that FGF23 is independently associated with LV mass index and LVH [44].

Referring to the CRIC study [32], higher C-terminal FGF23 levels were independently associated with reduced EF, greater LV mass index and prevalence of both eccentric and concentric LVH [32].

Several studies indicate a relationship between vitamin D, survival, vascular calcification and inflammation $[45,46]$, closely linked to the clinical features of CKD-MBD, together with a central role in the regulation of bone and mineral metabolism.

Vitamin D is also involved in the regulation of immune, cardiovascular, and endocrine systems through the activation of the high-affinity nuclear vitamin D receptor (VDR).

Due to the relevant role of vitamin D in heart disease, the association between LVH and VDR gene polymorphisms has recently been investigated, and it has been reported that VDR BsmI gene polymorphism is involved in the development of LVH in ESRD patients $[47,48]$ and is independently related to LVH progression in dialysis patients and in stage IIIb CKD patients. The presence of the BsmI mutated variant of the VDR gene in ESRD patients has been proposed as a novel marker of disrupted vitamin D signaling pathway, inducing an increase in the LV mass index [48]. Despite these pieces of evidence, it should be highlighted that the PRIMO study [49] failed to demonstrate any effect of paricalcitol on cardiac structure and LV function.

\section{Clinical Consequences of Increased LV Mass and Fibrosis in CKD and ESRD Patients}

As a consequence of $\mathrm{LVH}$, myocardial apoptosis, and intermyocardial fibrosis, the decrease in myocardial capillary density occurs together with diastolic (impaired diastolic filling of the ventricle to increased myocardial stiffness) and systolic dysfunction, disturbances in intraventricular conduction, and chamber dilation. Progressively, we might observe more compensatory hypertrophy, dilation and dysfunction of the heart (uremic cardiomyopathy) [18]. The severity and persistence of LVH are strongly associated with mortality risk and cardiovascular events in CKD and ESRD patients as reported by Zoccali et al. [50] and London et al. [51] who observed how a 10\% decrease in LV mass was translated into a $28 \%$ decrease in cardiovascular mortality risk in a cohort of patients on hemodialysis. The 
predictors of LVH regression include better control of systolic blood pressure, a lower pulse wave velocity and higher hemoglobin levels [52].

Despite the control of optimized risk factors (blood pressure, chronic ischemic heart disease and diabetes), sudden death often occurs in ESRD patients, which underlines that other factors (apart from coronary artery disease) have to be involved, such as LVH and myocardial fibrosis.

The presence of LVH has almost doubled the risk of sudden cardiac death in the patients enrolled in the 4D trial [52]. In this study, the authors show that the rising plasma levels of NT-pro-BNP have also been linked to sudden cardiac death together with the following factors:

- metabolic (e.g. hyperphosphatemia, hyperparathyroidism) and electrolyte (potassium, $\mathrm{pH}$ ) impairment,

- sympathetic overactivity,

- autonomic nerve dysfunction,

- concomitant obstructive sleep apnea,

- coronary artery calcification,

- acquired or hereditary QT interval prolongation,

- systolic and/or diastolic dysfunction,

- $\quad$ acute volume overload, and

- acute myocardial ischemia [17].

Autoptic studies in CKD patients show the presence of specific diffuse intermyocardiocyte fibrosis, not observed in similarly hypertensive patients without kidney disease [53]. $\mathrm{LVH}$ is strongly associated with poor outcomes in patients both with and without CKD; longitudinal and cross-sectional studies of LV mass underlines an increase in LVH prevalence as renal dysfunction develops [54].

Systolic hypertension and elevated pulse pressure are strongly associated with LVH in those patients with advanced CKD, suggesting that fluid overload and increased arterial stiffness play a role in LVH even before the start of dialysis therapy [53]. The younger age, the lower pulse pressure, and the higher GFR are related to a positive response to LV mass reduction [55]. Persistent or progressive LVH is strongly associated with an increase in the risk of mortality and cardiovascular events including sudden cardiac death in ESRD patients [50].

The reduction in the degree of $\mathrm{LVH}$ can be achieved by fluid balance and blood pressure control together with anemia control [56]. Foley et al. [57] found that improvements in LV mass and systolic function 1 year after the initiation of dialysis therapy were associated with reduction rates of cardiac failure but not ischemic cardiac events and death.

As confirming further, Covic et al. [58] reported a regression of LV mass in hemodialysis patients associated with improvements in anemia, serum phosphate level, and calcium-phosphate product.

Marchais et al. [59] found increased diastolic and mean arterial pressures, a higher cardiac index, higher heart rates, and an increased stroke index in hyperphosphatemic versus normophosphatemic patients. In fact, higher plasma phosphate is associated with signs of diastolic dysfunction and myocardial fibrosis and it is accountable for enhancing LVH; hence, hyperphosphatemia might be an appropriate target for treatment [60].

In conclusion, $\mathrm{LVH}$ develops beginning at early stages of CKD and it is quite common in patients on renal replacement therapy.

Although LV mass reduction is clearly associated with better rates of cardiovascular morbidity and mortality, it is not actually clear if scheduling more aggressive dialysis treatment could affect LVH development or regression [60]. 
Di Lullo et al.: Left Ventricular Hypertrophy in Chronic Kidney Disease Patients: From Pathophysiology to Treatment

\section{LVH Management in CKD and ESRD Patients: Key Messages}

Key principles in the treatment of LVH in CKD patients are mainly based on anemia and blood pressure control, together with the management of secondary hyperparathyroidism.

The impact of anemia therapy (with erythropoiesis-stimulating agents) on LVH in CKD and/or ESRD has been examined in several randomized controlled trials but most of them have failed to show any beneficial effect.

Parfrey et al. [61] reported a meta-analysis of 15 trials and showed how LV mass was reduced by anemia correction only in those subjects who had severe anemia at baseline $(<10$ $\mathrm{g} / \mathrm{dl})$ and who were treated to a lower target hemoglobin level $(<12 \mathrm{~g} / \mathrm{dl})$.

Chen et al. [62] compared the effects of epoetin alfa versus darbepoetin alfa on LVH in subjects with CKD. Both agents were equally effective in lowering LV mass. The correction of severe anemia (hemoglobin $<10 \mathrm{~g} / \mathrm{dl}$ ) with erythropoiesis-stimulating agents seems to attenuate $\mathrm{LVH}$ progression [63], but the achievement of hemoglobin levels $>12 \mathrm{~g} / \mathrm{dl}$ does not help reduce the LV mass.

Maintaining the systolic blood pressure at normal levels ( $<140 \mathrm{~mm} \mathrm{Hg}$ ) [64-66] and the optimal fluid volume balance near the euvolemic state [67] is predicted to have beneficial effects on the course of LVH in CKD and ESRD subjects.

The correction of abnormalities in divalent ion metabolism in CKD and ESRD (including vitamin D deficiency, hyperphosphatemia and hyperparathyroidism) might have beneficial effects on LVH, but there are no clinical trials at our disposal [68]. Patients receiving vitamin D therapy show a lower frequency of cardiovascular events and improved survival in observational studies [68]. Furthermore, several trials have detected that higher PTH levels (intact PTH levels $>500 \mathrm{pg} / \mathrm{ml}$ ) are associated with failure of LVH regression [58].

Although the EVOLVE trial has not shown that cinacalcet improves survival in ESRD patients, a post hoc analysis suggests that this drug that lowers PTH may also lower the risk of sudden cardiac death and/or cardiac failure [69].

Another key point in the management of LVH is to better manage hemodialysis sessions and peritoneal dialysis exchanges. More frequent hemodialysis (including short daily or long nocturnal dialysis) has been suggested as a new paradigm of treatment [70-72], and observational studies have shown how more frequent and longer hemodialysis sessions are associated with a lower prevalence of LVH [70-72].

As previously discussed, sudden cardiac death mainly accounts for cardiovascular mortality in ESRD [73]. Small randomized controlled trials showed a reduction in sudden cardiac death from 10.4 to $3.4 \%$ with carvedilol in ESRD patients with dilated cardiomyopathy [74], although further larger trials with $\beta$-blockers are needed. $\beta$-Blocker therapy should be routinely used in CKD and ESRD patients with prior nonfatal coronary artery ischemic events. An independent trial has shown a risk reduction of sudden cardiac death associated with sevelamer [75].

In conclusion, more clinical trials are needed to assess guidelines for treating CKD-related hypertrophic cardiomyopathy. At the present time, it is quite difficult to sort out regression parameters of LVH both in experimental and clinical models.

\section{Diagnosis and Assessment of LVH}

Electrocardiography, 2D (fig. 1, 2) and 3D echocardiography (ECHO) and cardiac magnetic resonance imaging (CMRI) represent three next steps to quantify and estimate the degree of LVH. 
CardioRenal Medicine

Fig. 1. 2D ECHO (four-chamber apical view) showing $\mathrm{LVH}$ in a stage IIIb CKD patient.

\begin{tabular}{l|l}
\hline Cardiorenal Med 2015;5:254-266 \\
\hline DOI: 10.1159/000435838 & $\begin{array}{l}\text { @ 2015 S. Karger AG, Basel } \\
\text { www.karger.com/crm }\end{array}$ \\
\hline
\end{tabular}

Di Lullo et al.: Left Ventricular Hypertrophy in Chronic Kidney Disease Patients: From Pathophysiology to Treatment
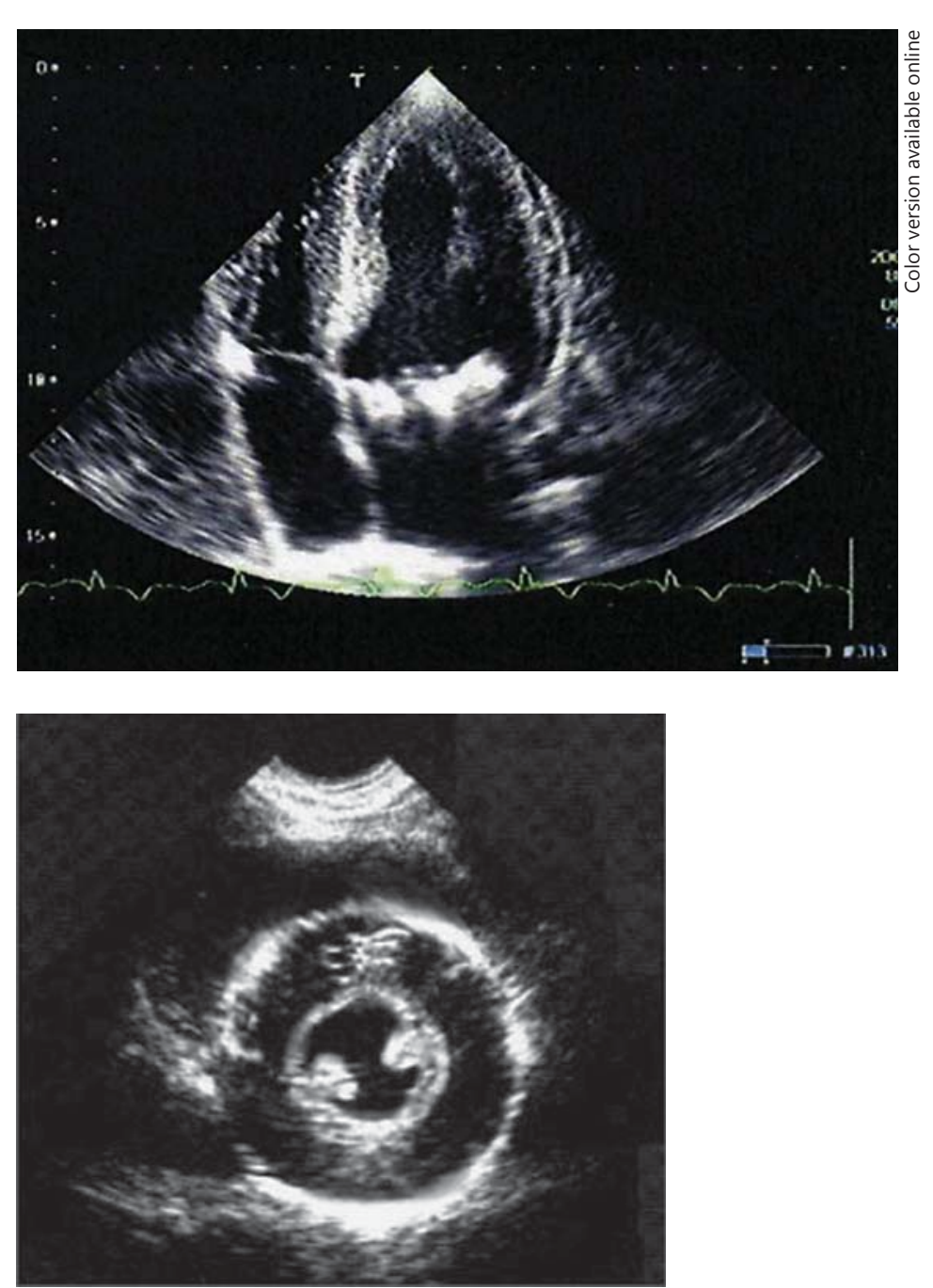

Fig. 2. 2D ECHO (short-axis view) showing LVH in a hemodialysis patient.

patient.

Historically, electrocardiography was the first test employed to evaluate LVH because it is noninvasive, cheap and easily performed by nurses and physicians. It is considered an insensitive but quite specific method, although the criteria for ruling out LVH are not satisfactory [76].

On the other hand, CMRI represents the gold standard to evaluate LV dimensions because it is accurate in defining LV mass as well as the volume and pattern of LVH (eccentric, concentric or asymmetric). It may also assess the degree of fibrosis.

In hemodialysis patients, M-mode ECHO often overestimates LV mass compared to CMRI [77]; however, at present, the use of CMRI is not widespread due to its costs and side effects such as claustrophobia. Moreover, it cannot be employed in the presence of implantable devices [78].

Because of these clear limits of CMRI, ECHO is still established as the main device to evaluate LV mass in daily clinical practice although there are limitations in the determination and quantification of LVH. The accuracy of ECHO depends on:

- the technique used,

- the timing relative to the dialysis session, and

- the index used for the 'normalization' of generated data. 
Therefore, ECHO is subject to the skills of the operator, the patients' acoustic windows and other errors during the generation of images in the case of an asymmetric LV geometry pattern $[78,79]$.

Variability in LV mass determination is due to the normalization index adopted. In fact, the ventricular mass is proportional to the body size, and it is necessary to use the body surface for the correction (as is commonly done in clinical studies and in clinical practice).

Various cutoff values were used in different trials: for example, Silberberg et al. [80] used a cutoff value of $125 \mathrm{~g} / \mathrm{m}^{2}$ for the diagnosis of LVH by ECHO, whereas Parfrey et al. [81] used a value of $132 \mathrm{~g} / \mathrm{m}^{2}$ for men and $100 \mathrm{~g} / \mathrm{m}^{2}$ for women (referring to the Framingham study).

Recent guidelines redefined normal values of $\operatorname{LV}$ mass as $<45 \mathrm{~g} / \mathrm{m}$ height $[76,79]$ for women and $<49 \mathrm{~g} / \mathrm{m}$ height $[76,82$ ] for men using ECHO [83]. 2D ECHO is based on geometric assumptions and is highly dependent on adequate endocardial and epicardial border definition of the LV. Real-time 3D ECHO allows a more precise assessment of the LV mass, volume and EF [83]. In comparison to other methods, 3D ECHO is nearly as accurate as CMRI [84].

In conclusion, ECHO and CMRI may be complementary in the evaluation of intermyocardial fibrosis and diastolic dysfunction in CKD and ESRD subjects [76]. CMRI is able to detect and quantify the presence of myocardial fibrosis, as indicated by late gadolinium enhancement, although it should be avoided in patients with late-stage CKD [85].

CMRI represents the best method for detecting and quantifying increased LV mass in CKD and ESRD patients. However, it is expensive and presents some practical restrictions, while M-mode ECHO or 2D ECHO are widely employed because they are cheaper and noninvasive tools.

\section{Conclusions}

LVH is a typical feature of CKD-related cardiopathy. It can be defined as the final result of several pathophysiological pathways leading to cell thickening and concentric LV remodeling. Activation of the renin-angiotensin system, inhibition of nitric oxide synthesis, intravascular volume expansion, secondary anemia, and the presence of arterovenous fistulas can be accountable both for myocardial cell lengthening and eccentric or asymmetric LV development up to LV fibrosis. On the other hand, FGF23 and vitamin D play a crucial role in LV hypertrophy development although pathophysiological pathways are not completely defined at the present time.

According to clinical evidence, $\mathrm{LVH}$ and myocardial fibrosis are associated with mortality risk and cardiovascular events in CKD and ESRD such as demonstrated by higher rates of sudden cardiac death in these patients.

Finally, treatment of LVH is mainly based on anemia and blood pressure control, together with the management of secondary hyperparathyroidism and optimization of renal replacement therapy maximization.

\section{Disclosure Statement}

All authors have no conflicts of interest to declare. 


\section{CardioRenal Medicine}

\begin{tabular}{l|l}
\hline \multicolumn{2}{l}{ Cardiorenal Med 2015;5:254-266 } \\
\hline DOI: 10.1159/000435838 & $\begin{array}{l}\text { C) 2015 S. Karger AG, Basel } \\
\text { www.karger.com/crm }\end{array}$ \\
\hline
\end{tabular}

Di Lullo et al.: Left Ventricular Hypertrophy in Chronic Kidney Disease Patients: From Pathophysiology to Treatment

\section{References}

1 Ronco C: The cardiorenal syndrome: basis and common ground for a multidisciplinary patient-oriented therapy. Cardiorenal Med 2011;1:3-4.

-2 Heywood JT, Fonarow GC, Costanzo MR, Mathur VS, Wigneswaran JR, Wynne J; ADHERE Scientific Advisory Committee and Investigators: High prevalence of renal dysfunction and its impact on outcome in 118,465 patients hospitalized with acute decompensated heart failure: a report from the ADHERE database. J Card Fail 2007;13:422-430.

-3 Garg AX, ClarkWF, Haynes RB, House AA: Moderate renal insufficiency and the risk of cardiovascular mortality: results from the NHANES I. Kidney Int 2002;61:1486-1494.

$\checkmark 4$ Foley RN, Parfrey PS, Harnett JD, Kent GM, Murray DC, Barre PE: The prognostic importance of left ventricular geometry in uremic cardiomyopathy. J Am Soc Nephrol 1995;5:2024-2031.

5 Harnett JD, Foley RN, Kent GM, Barre PE, Murray D, Parfrey PS: Congestive heart failure in dialysis patients: prevalence, incidence, prognosis and risk factors. Kidney Int 1995;47:884-890.

6 US Renal Data System: USRDS 2012 Annual Data Report: Atlas of End-Stage Renal Disease in the United States. Bethesda, National Institutes of Health, National Institute of Diabetes and Digestive and Kidney Diseases, 2012.

7 Tonelli M, Wiebe N, Culleton B, House A, Rabbat C, Fok M, McAlister F, Garg AX: Chronic kidney disease and mortality risk: a systematic review. J Am Soc Nephrol 2006;17:2034-2047.

8 US Renal Data System: USRDS 2009 Annual Data Report: Atlas of End-Stage Renal Disease in the United States. Bethesda, National Institutes of Health, National Institute of Diabetes and Digestive and Kidney Diseases, 2009.

9 Go AS, Chertow GM, Fan D, McCulloch CE, Hsu CY: Chronic kidney disease and the risks of death, cardiovascular events, and hospitalization. N Engl J Med 2004;351:1296-1305.

10 Shastri S, Sarnak MJ: Cardiovascular disease and CKD: core curriculum 2010. Am J Kidney Dis 2010;56:399417.

11 Stevens LA, Li S, Wang C, Huang C, Becker BN, Bomback AS, Brown WW, Burrows NR, Jurkovitz CT, McFarlane SI, Norris KC, Shlipak M, Whaley-Connell AT, Chen SC, Bakris GL, McCullough PA: Prevalence of CKD and comorbid illness in elderly patients in the united states: results from the kidney early evaluation program (KEEP). Am J Kidney Dis 2010;55(3 suppl 2):S23-S33.

-12 Bansal N, Keane M, Delafontaine P, Dries D, Foster E, Gadegbeku CA, Go AS, Hamm LL, Kusek JW, Ojo AO, Rahman M, Tao K, Wright JT, Xie D, Hsu CY; CRIC Study Investigators: A longitudinal study of left ventricular function and structure from CKD to ESRD: the CRIC study. Clin J Am Soc Nephrol 2013;8:355-362.

13 Kottgen A, Russell SD, Loehr LR, Crainiceanu CM, Rosamond WD, Chang PP, Chambless LE, Coresh J: Reduced kidney function as a risk factor for incident heart failure: the atherosclerosis risk in communities (ARIC) study. J Am Soc Nephrol 2007;18:1307-1315.

14 Di Lullo L, Floccari F, Polito P: Right ventricular diastolic function in dialysis patients could be affected by vascular access. Nephron Clin Pract 2011;118:c258-c262.

15 Foley RN, Curtis BM, Randell EW, Parfrey PS: Left ventricular hypertrophy in new hemodialysis patients without symptomatic cardiac disease. Clin J Am Soc Nephrol 2010;5:805-813.

-16 Parikh SV, de Lemos JA: Biomarkers in cardiovascular disease: integrating pathophysiology into clinical practice. Am J Med Sci 2006;332:186-197.

17 Ritz E, Wanner C: The challenge of sudden death in dialysis patients. Clin J Am Soc Nephrol 2008;3:920-929.

18 Gross ML, Ritz E: Hypertrophy and fibrosis in the cardiomyopathy of uremia - beyond coronary heart disease. Semin Dial 2008;21:308-318.

19 Ritz E: Left ventricular hypertrophy in renal disease: beyond preload and afterload. Kidney Int 2009;75:771773.

20 Mominadam S, et al: Interdialytic blood pressure obtained by ambulatory blood pressure measurement and left ventricular structure in hypertensive hemodialysis patients. Hemodial Int 2008;12:322-327.

21 Steigerwalt S, Zafar A, Mesiha N, Gardin J, Provenzano R: Role of aldosterone in left ventricular hypertrophy among African-American patients with end-stage renal disease on hemodialysis. Am J Nephrol 2007;27:159163.

22 Xu X, Hu X, Zhang P, Zhao L, Wessale JL, Bache RJ, Chen Y: Xantine oxidase inhibition with febuxostat attenuates systolic overload-induced left ventricular hypertrophy and dysfunction in mice. J Card Fail 2008;14:746-753.

23 Hsu S, Nagayama T, Koitabashi N, Zhang M, Zhou L et al: Phosphodiesterase-5 inhibition blocks pressure overload-induced cardiac hypertrophy independent of the calcineurin pathway. Cardiovasc Res 2009;81: 301-309.

-24 Martin LC, Franco RJ, Gavras I, Matsubara BB, Garcia S, Caramori JT, Barretti BB, Balbi AR, Barsanti R, Padovani C, Gavras H: Association between hypervolemia and ventricular hypertrophy in hemodialysis patients. Am J Hypertens 2004;17:1163-1169.

25 McRae JM, Levin A, Belenkie I: The cardiovascular effects of arteriovenous fistulas in chronic kidney disease. A cause for concern? Semin Dial 2006;19:349-352.

26 Nishida K, Kyoi S, Yamaguchi O, Sadoshima J, Otsu K: The role of autophagy in the heart. Cell Death Differ 2009; 16:31-38. 


\section{CardioRenal Medicine}

\begin{tabular}{l|l}
\hline \multicolumn{2}{l}{ Cardiorenal Med 2015;5:254-266 } \\
\hline DOI: $10.1159 / 000435838$ & $\begin{array}{l}\text { C 2015 S. Karger AG, Basel } \\
\text { www.karger.com/crm }\end{array}$ \\
\hline
\end{tabular}

Di Lullo et al.: Left Ventricular Hypertrophy in Chronic Kidney Disease Patients: From Pathophysiology to Treatment

27 Dorm GW 2nd: Apoptotic and non-apoptotic programmed cardiomyocyte death in ventricular remodeling. Cardiovasc Res 2009;81:465-473.

28 Zoccali C, Benedetto FA, Tripepi G, Mallamaci F: Cardiac consequences of hypertension in hemodialysis patients. Semin Dial 2004;17:299-303.

29 Sakurabayashi T, Miyazaki S, Yuasa Y, Sakai S, Suzuki M, Takahashi S, Hirasawa Y: L-Carnitine supplementation decreases the left ventricular mass in patients undergoing hemodialysis. Circ J 2008;72:926-931.

-30 Strozecki P, et al: Parathormon, calcium, phosphorus and left ventricular structure and function in normotensive hemodialysis patients. Ren Fail 2001;23:115-126.

-31 Koleganova N, Piecha G, Ritz E, Bekeredjian R, Schirmacher P, Schmitt CP, Gross ML: Interstitial fibrosis and microvascular disease of the heart in uremia: amelioration by a calciomimetic. Lab Invest 2009;89:520-530.

-32 Oberleithner H, Riethmuller C, Schillers H, Mac Gregor GA, de Wardener HE, Hausberg M: Plasma sodium stiffens vascular endothelium and reduces nitric oxide release. Proc Natl Acad Sci USA 2007;104:1628116286.

-33 De Paula FM, Peixoto AJ, Pinto LV, Dorigo D, Patricio PJ, Santos SF: Clinical consequences of an individualized dialysate sodium prescription in hemodialysis patients. Kidney Int 2004;66:1232-1238.

34 Moe S, Drueke T, Cunningham J: Definition, evaluation and classification of renal osteodistrophy: a position statement from Kidney Disease Improving Global Outcome (KDIGO). Kidney Int 2006;69:1945-1953.

-35 Moe S, Drueke TB, Block A, et al: KDIGO clinical practice guideline for the diagnosis, evaluation, prevention and treatment of chronic kidney disease-mineral and bone disorder (CKD-MBD). Kidney Int 2009;113:S1S130.

-36 Burhiya R, Li S, Chen S, Mc Cullough PA, Bakris GL: Plasma parathyroid hormone level and prevalent cardiovascular disease in CKD stages 3 and 4: an analysis from the Kidney Early Evaluation Program (KEEP). Am J Kidney Dis 2009;53:S3-S10.

37 Evenepoel P, Meijers B, Viaene L, et al: Fibroblast growth factor-23 in early chronic kidney disease: additional support in favor of a phosphate-centric paradigm for the pathogenesis of secondary hyperparathyroidism. Clin J Am Soc Nephrol 2010;5:1268-1276.

-38 Isakova T, Wahl P, Vargas GS: Fibroblast growth factor-23 is elevated before parathyroid hormone and phosphate in chronic kidney disease. Kidney Int 2011;79:1370-1378.

39 Faul C, Amaral AP, Oskouei B, et al: FGF23 induces left ventricular hyperthrophy. J Clin Invest 2011;12:43934408.

40 Gutierrez OM, Mannstadt M, Isakova T, et al: Fibroblast growth factor 23 and mortality among patients undergoing hemodialysis. N Engl J Med 2008;359:584-592.

41 Isakova T, Xie H, Yang W: Fibroblast growth factor 23 and risks of mortality and end-stage renal disease in patients with chronic kidney disease. JAMA 2011;305:2432-2439.

$\checkmark 42$ Liu X, Xie R, Liu S: Rat parathyroid hormone 1-34 signals through the MEK/ERK pathway to induce cardiac hypertrophy. J Int Med Res 2008;36:942-950.

43 Moon KH, Song IS, Yang WS, Shin YT, Kim SB, Song JK, Park JS: Hypoalbuminemia as a risk factor for progressive left-ventricular hypertrophy in hemodialysis patients. Am J Nephrol 2000;20:396-401.

44 Chmielewski M, Carrero JJ, Stenvinkel P, Lindholm B: Metabolic abnormalities in chronic kidney disease that contribute to cardiovascular disease, and nutritional initiatives that may diminish the risk. Curr Opin Lipidol 2009;20:3-9.

45 Wolf M, Shah A, Gutierrez O, Ankers E, Monroy M, Tamez H, Steele D, Chang Y, Camargo CA Jr, Tonelli M, Thadhani R: Vitamin D levels and early mortality among incident hemodialysis patients. Kidney Int 2007;72: 1004-1013.

46 Mehrotra R, Kermah D, Budoff M, Salusky IB, Mao SS, Gao YL, Takasu J, Adler S, Norris K: Hypovitaminosis D in chronic kidney disease. Clin J Am Soc Nephrol 2008;3:1144-1151.

47 Testa A, Mallamaci F, Benedetto F, Pisano A, Tripepi G, Malatino L, Thadhani R, Zoccali C: Vitamin D receptor (VDR) gene polymorphism is associated with left ventricular (LV) mass and predicts left ventricular hypertrophy (LVH) progression in end-stage renal disease (ESRD) patients. J Bone Miner Res 2010;25:313-319.

-48 El-Shehaby AM, El-Khatib MM, Marzouk S, Battah AA: Relationship of BsmI polymorphism of vitamin D receptor gene with left ventricular hypertrophy and atherosclerosis in hemodialysis patients. Scand J Clin Lab Invest 2013;73:75-81.

-49 Thadhani R, Appelbaum E, Pritchett Y, Chang Y, Wenger J, Tamez H, Bhan I, Agarwal R, Zoccali C, Wanner C, Lloyd-Jones D, Cannata J, Thompson BT, Andress D, Zhang W, Packham D, Singh B, Zehnder D, Shah A, Pachika A, Manning WJ, Solomon SD: Vitamin D therapy and cardiac structure and function in patients with chronic kidney disease: the PRIMO randomized controlled trial. JAMA 2012;307:674-684.

50 Zoccali C, Benedetto FA, Mallamaci F, Tripepi G, Giacone G, Stancanelli B, Cataliotti A, Malatino LS: Left ventricular mass monitoring in the follow-up of dialysis patients: prognostic value of left ventricular hypertrophy progression. Kidney Int 2004;65:1492-1498.

-51 London GM, Pannier B, Guerin AP, Blacher J, Marchais SJ, Darne B, Metivier F, Adda H, Safar ME: Alterations of left ventricular hypertrophy in and survival of patients receiving hemodialysis: follow-up of an interventional study. J Am Soc Nephrol 2001;12:2759 -2767.

52 Krane V, Winkler K, Drechsler C, Lilienthal J, Marz W, Wanner C: Effect of atorvastatin on inflammation and outcome in patients with type 2 diabetes mellitus on hemodialysis. Kidney Int 2008;74:1461-1467. 


\section{CardioRenal Medicine}

\begin{tabular}{l|l}
\hline Cardiorenal Med 2015;5:254-266 \\
\hline DOI: 10.1159/000435838 & $\begin{array}{l}\text { ○ 2015 S. Karger AG, Basel } \\
\text { www.karger.com/crm }\end{array}$ \\
\hline
\end{tabular}

Di Lullo et al.: Left Ventricular Hypertrophy in Chronic Kidney Disease Patients: From Pathophysiology to Treatment

53 Aoki J, Ikari Y, Nakajima H, Mori M, Sugimoto T, Hatori M, Tanimoto S, Amiya E, Hara K: Clinical and pathologic characteristics of dilated cardiomyopathy in hemodialysis patients. Kidney Int 2005;67:333-340.

54 Paoletti E, Bellino D, Cassottana P, Rolla D, Cannella G: Left ventricular hypertrophy in nondiabetic predialysis CKD. Am J Kidney Dis 2005;46:320-327.

55 McMahon LP, Roger SD, Levin A: Development, prevention, and potential reversal of left ventricular hypertrophy in chronic kidney disease. J Am Soc Nephrol 2004;15:1640-1647.

56 Culleton BF, Walsh M, Klarenbach SW, Mortis G, Scott-Douglas N, Quinn RR, Tonelli M, Donnelly S, Friedrich MG, Kumar A, Mahallati H, Hemmelgarn BR, Manns BJ: Effect of frequent nocturnal hemodialysis vs conventional hemodialysis on left ventricular mass and quality of life: a randomized controlled trial. JAMA 2007;298: 1291-1299.

57 Foley RN, Parfrey PS, Kent GM, Harnett JD, Murray DC, Barre PE: Serial change in echocardiographic parameters and cardiac failure in end-stage renal disease. J Am Soc Nephrol 2000;11:912-916.

$\$ 58$ Covic A, Mardare NG, Ardeleanu S, Prisada O, Gusbeth-Tatomir P, Goldsmith DJ: Serial echocardiographic changes in patients on hemodialysis: an evaluation of guideline implementation. J Nephrol 2006;19:783-793.

59 Marchais SJ, Metivier F, Guerin AP, London GM: Association of hyperphosphataemia with haemodynamic disturbances in end-stage renal disease. Nephrol Dial Transplant 1999;14:2178-2183.

-60 Galetta F, Cupisti A, Franzoni F, Femia FR, Rossi M, Barsotti G, Santoro G: Left ventricular function and calcium phosphate plasma levels in uraemic patients. J Intern Med 2005;258:378-384.

61 Parfrey PS, Lauve M, Latremouille-Viau D, Lefebvre P: Erythropoietin therapy and left ventricular mass index in CKD and ESRD patients: a meta-analysis. Clin J Am Soc Nephrol 2009;4:755-762.

-62 Chen HH, Tarng DC, Lee KF, Wu CY, Chen YC: Epoetin alfa and darbepoetin alfa: Effects on ventricular hypertrophy in patients with chronic kidney disease. J Nephrol 2008;21:543-549.

-63 Ayus JC, Go AS, Valderrabano F, Verde E, de Vinuesa SG, Achinger SG, Lorenzo V, Arieff AI, Luno J: Effects of erythropoietin on left ventricular hypertrophy in adults with severe chronic renal failure and hemoglobin 10 g/dl. Kidney Int 2005;68:788-795.

64 Mattioli AV, Zennaro M, Bonatti S, Bonetti L, Mattioli G: Regression of left ventricular hypertrophy and improvement of diastolic function in hypertensive patients treated with telmisartan. Int J Cardiol 2004;97: 383-388.

65 Devereux RB, Palmieri V, Liu JE, Wachtell K, Bella JN, Boman K, Gerdts E, Nieminen MS, Papademetriou V, Dahlof B: Progressive hypertrophy regression with sustained pressure reduction in hypertension: the Losartan Intervention for Endpoint Reduction study. J Hypertens 2002;20:1445-1450.

66 Jula AM, Karanko HM: Effects on left ventricular hypertrophy of long-term nonpharmacological treatment with sodium restriction in mild-to-moderate essential hypertension. Circulation 1994;89:1023-1031.

-67 Charra B, Chazot C: Volume control, blood pressure and cardiovascular function. Lessons from hemodialysis treatment. Nephron Physiol 2003;93:94 -101.

68 Achinger SG, Ayus JC: The role of vitamin D in left ventricular hypertrophy and cardiac function. Kidney Int 2005;68:(suppl):S37-S42.

69 Wheeler DC, London GM, Parfrey PS, Block GA, Correa-Rotter R, Dehmel B, Drüeke TB, Floege J, Kubo Y, Mahaffey KW, Goodman WG, Moe SM, Trotman ML, Abdalla S, Chertow GM, Herzog CA: Effects of cinacalcet on atherosclerotic and nonatherosclerotic cardiovascular events in patients receiving hemodialysis: the Evaluation of Cinacalcet HCl Therapy to Lower Cardiovascular Events (EVOLVE) trial. J Am Heart Assoc 2014; 3:e001363.

70 Ly J, Chan CT: Impact of augmenting dialysis frequency and duration on cardiovascular function. ASAIO J 2006; 52:e11-e14.

71 Fagugli RM, Pasini P, Pasticci F, Ciao G, Cicconi B, Buoncristiani U: Effects of short daily hemodialysis and extended standard hemodialysis on blood pressure and cardiac hypertrophy: a comparative study. J Nephrol 2006;19:77-83.

72 Weinreich T, De los Rios T, Gauly A, Passlick-Deetjen J: Effects of an increase in time vs frequency on cardiovascular parameters in chronic hemodialysis patients. Clin Nephrol 2006;66:433-439.

73 Kong CH, Farrington K: Determinants of left ventricular hypertrophy and its progression in high-flux haemodialysis. Blood Purif 2003;21:163-169.

74 Cice G, Ferrara L, D’Andrea A, D’Isa S, Di Benedetto A, Cittadini A, Russo PE, Golino P, Calabro R: Carvedilol increases two-year survival in dialysis patients with dilated cardiomyopathy: a prospective, placebocontrolled trial. J Am Coll Cardiol 2003;41:1438-1444.

75 Di Iorio B, Molony D, Bell C, Cucciniello E, Bellizzi V, Russo D, Bellasi A; INDEPENDENT Study Investigators: Sevelamer versus calcium carbonate in incident hemodialysis patients: results of an open-label 24-month randomized clinical trial. Am J Kidney Dis 2013;62:771-778.

-76 Pewsner D, Juni P, Egger M, Battaglia M, Sundstrom J, Bachmann LM: Accuracy of electrocardiography in diagnosis of left ventricular hypertrophy in arterial hypertension: systematic review. BMJ 2007;335:711.

-77 Stewart GA, Foster J, Cowan M, Rooney E, McDonagh T, Dargie HJ, Rodger RS, Jardine AG: Echocardiography overestimates left ventricular mass in hemodialysis patients relative to magnetic resonance imaging. Kidney Int 1999;56:2248 -2253.

-78 Mark PB, Patel RK, Jardine AG: Are we overestimating left ventricular abnormalities in end-stage renal disease? Nephrol Dial Transplant 2007;22:1815-1819. 
79 Zoccali C, Benedetto FA, Mallamaci F, Tripepi G, Giacone G, Cataliotti A, Seminara G, Stancanelli B, Malatino LS: Prognostic impact of the indexation of left ventricular mass in patients undergoing dialysis. J Am Soc Nephrol 2001;12:2768-2774

80 Silberberg JS, Barre PE, Prichard SS, Sniderman AD: Impact of left ventricular hypertrophy on survival in endstage renal disease. Kidney Int 1989;36:286 -290.

-81 Parfrey PS, Foley RN, Harnett JD, Kent GM, Murray DC, Barre PE: Outcome and risk factors for left ventricular disorders in chronic uraemia. Nephrol Dial Transplant 1996;11:1277-1285.

82 Ritz E, Bommer J: Cardiovascular problems on hemodialysis: current deficits and potential improvement. Clin J Am Soc Nephrol 2009;4:S71-S78.

83 Lang RM, Bierig M, Devereux RB, Flachskampf FA, Foster E, Pellikka PA, Picard MH, Roman MJ, Seward J, Shanewise JS, Solomon SD, Spencer KT, Sutton MS, Stewart WJ: Recommendations for chamber quantification: a report from the American Society of Echocardiography's Guidelines and Standards Committee and the Chamber Quantification Writing Group, developed in conjunction with the European Association of Echocardiography, a branch of the European Society of Cardiology. J Am Soc Echocardiogr 2005;18:1440-1463.

84 Takeuchi M, Nishikage T, Mor-Avi V, Sugeng L, Weinert L, Nakai H, Salgo IS, Gerard O, Lang RM: Measurement of left ventricular mass by real-time three-dimensional echocardiography: validation against magnetic resonance and comparison with two-dimensional and m-mode measurements. J Am Soc Echocardiogr 2008;21: 1001-1005.

85 Kribben A, Witzke 0, Hillen U, Barkhausen J, Daul AE, Erbel R: Nephrogenic systemic fibrosis: pathogenesis, diagnosis, and therapy. J Am Coll Cardiol 2009;53:1621-1628. 